Gut, 1982, 23, 89-97

\title{
Diagnosis of oesophageal spasm by ergometrine provocation
}

\author{
H ALBAN DAVIES, M D KAYE, ${ }^{*} J$ RHODES, A M DART, AND A H HENDERSON \\ From the Departments of Gastroenterology and Cardiology, University Hospital of Wales and \\ Welsh National School of Medicine, Cardiff
}

SUMMARY Oesophageal spasm may mimic the pain of myocardial ischaemia. Forty-two patients who were thought to have angina until investigations failed to show any cardiovasular abnormality, were examined for oesophageal disease. Ergometrine provocation during oesophageal manometry caused significant deterioration in oesophageal motility, associated with familiar pain, in 24 patients. Ten age-matched controls were examined in a similar way and ergometrine produced motility changes in four and pain in two. Six volunteers with coronary artery stenosis and exercise-induced angina did not develop oesophageal motility changes during the pain. Ergometrine provocation is useful in establishing the diagnosis of oesophageal spasm in patients with recurrent angina-like pain but no cardiac abnormality.

No 'gold standard' can be applied to confirm the diagnosis of oesophageal spasm. Patients with suggestive symptoms may be investigated many times before any abnormality is found, while other, asymptomatic, subjects have disorders of oesophageal motility demonstrated by chance. The clinical features of oesophageal spasm may also be misleading: the pain is typically anginal in character and in the absence of dysphagia a mistaken diagnosis of myocardial ischaemia is easily made.

It would be of great value to diagnose this condition more accurately and provocative tests may be of particular help because relevant observations can be made while the symptoms are present. In this study $\mathbf{4 2}$ patients who presented with chest pain of anginal character, but had no cardiovascular abnormality, were assessed by standard oesophageal manometry and barium swallow examination. Ergometrine (Ergonovine), which stimulates smooth muscle contraction and has an established place in the diagnosis of coronary artery spasm, was then given as a provocative test while oesophageal pressure was measured; control observations were obtained in a group of normal volunteers. In another group of patients with coronary artery stenosis, oesophageal manometry was recorded after exercise to establish whether or not abnormalities of oesophageal motility developed during exertional angina.

- Present address: Department of Medicine. University of Vermont College of Medicine. USA.

Received for publication 22 June 1981
Methods

\section{SUBJECTS}

Chest pain group

This comprised 42 patients with severe chest pain who had been followed up for between two and five years with suspected angina despite the absence of any relevant cardiovascular abnormality. Almost all of them had emergency admissions to hospital with suspected, but unsubstantiated, myocardial infarction There were 21 males (average age 45 years) and 21 females (average age 49 years). Thirty-seven of them were followed up in the Cardiology Department and had normal coronary arteriograms, the other five patients were referred directly by general physicians. The angina-like chest pain was brought on by exercise and emotion and relieved by nitrates in more than $90 \%$ of the group; none of the patients presented to his doctor complaining of oesophageal problems, although, on questioning, $38 \%$ admitted to dysphagia and $52 \%$ had heartburn or fluid regurgitation.

All patients had an exercise test (Bruce protocol) and, although 10 were unable to complete this because of fatigue or breathlessness rather than chest pain, adequate heart rates of $>150 / \mathrm{min}$ were achieved in every case. There were no cardiographic signs of myocardial ischaemia at rest, during exercise, during the patient's pain, or after ergometrine, although nonspecific changes (ST depression $<2 \mathrm{~mm}$ or T wave inversion) were seen in 10 patients. Thirty-seven of the group had coronary angiograms and all were normal or showed insignificant lesions ( $<50 \%$ narrowing). 
When ergometrine was given, 23 of these 37 developed pain, but another angiogram after ergometrine showed that this was not associated with coronary artery spasm.

In all 37 patients transmyocardial lactate measurements were made to assess the effect of ergometrine and rapid atrial pacing on myocardial metabolism. There was no evidence of cardiovasular disease apart from mild hypertension in eight and rheumatic heart disease in one patient. One patient was a diabetic controlled on diet and hypoglycaemic drugs.

\section{Control group $A$}

Ten volunteers (six males, average age 36 years; four females, average age 47 years) with no oesophageal symptoms first performed a normal exercise test and then underwent the manometric studies described below.

\section{Control group B}

Six volunteers (all males, average age 45 years), who were patients with angina and significant coronary artery stenosis which had been established by angiography, performed an exercise test during oesophageal studies. They were not given ergometrine.

\section{TECHNIQUES}

System for measuring oesophageal motility

A triple lumen tube of $6 \mathrm{~mm}$ external diameter was perfused with water at $0.5 \mathrm{ml} / \mathrm{min} /$ channel by a syringe pump (Palmer, F-133). Channels opened at the tip, $5 \mathrm{~cm}$ and $10 \mathrm{~cm}$ proximal to this; the openings were orientated radially at $120^{\circ}$ to each other and pressure was measured in each channel by Statham Db strain gauges and recorded on an oscillograph (Devices M4) after calibration with a sphygmomanometer. The rate of rise of pressure recorded after occluding an opening with a finger tip was $590 \mathrm{~mm}$ $\mathrm{Hg} / \mathrm{s}$. Repiratory movements were recorded by a belt pneumograph and subjects were instructed to press an event marker to indicate swallows.

The catheter was passed nasally and the gastrooesophageal junction examined by station pull-back from the stomach with the patient supine. Resting lower oesophageal sphincter pressure (LOSP), measured at the mid-point of the respiratory cycle with gastric pressure as zero, was taken to be the average of the three recordings obtained. The tube was anchored with the distal opening positioned in the lower oesophageal sphincter (LOS) for the rest of the study.

Subjects were instructed to report any symptoms and, after a period of base-line observations, $2 \mathrm{ml}$ normal saline was given intravenously and the patients observed for five minutes. Ergometrine (Ergonovine)
$0.5 \mathrm{mg}$ to $1 \mathrm{mg}$, was then given by slow intravenous injection while monitoring the 12-lead electrocardiogram; all swallows were 'dry' during both injection periods. Full resuscitation facilities, including intravenous isosorbide dinitrate, were available and two doctors with experience in resuscitation techniques were present.

If patients reported chest pain the precise time of onset and relief was recorded and the clinician established whether it was similar to the presenting complaint.

The oesophageal manometric records of the 42 patients and the 10 group A controls were each cut into three traces of equal length featuring the pullthrough and base line, the control (saline injection), and the ergometrine injection periods. All writing apart from technical observations was masked and the traces were interpreted 'blind' by an experienced observer (MDK) who was unaware which tracings corresponded to saline and ergometrine injections, whether chest pain occurred, and to which group individuals belonged.

\section{Interpretation of oesophageal motility traces}

Traces were described as normal, showing spasm, or non-specific abnormality.

\section{SPASM}

Major criteria for inclusion in this category were either (1) the presence of prolonged (duration $>12 \mathrm{~s}$ ) and powerful (amplitude $>50 \mathrm{~mm} \mathrm{Hg}$ ) post-deglutitive contractions, or (2) runs of frequent spontaneous contractions, often with a rise of oesophageal baseline pressure; many traces showed both of these abnormalities. In all cases there was an abnormal frequency $(>10 \%)$ of simultaneous contractions, and in none were amplitudes less than $40 \mathrm{~mm} \mathrm{Hg}$. Repetitive contractions were frequent, and in some traces LOS contraction was abnormal in duration and amplitude.

Four traces which showed an increase of LOSP from the normal range ( $<35 \mathrm{~mm} \mathrm{Hg}$ ) to greater than $40 \mathrm{~mm} \mathrm{Hg}$ were subsequently also included in this category (Fig. 1). Transient increases of LOSP which occurred within 30 seconds of the swallow, and represented sphincter contraction were ignored.

\section{NON-SPECIFIC ABNORMALITIES}

These did not conform to any specific manometric diagnosis. They were often minor and included combinations of the following: an abnormal $(>10 \%)$ frequency of simultaneous post-deglutitive contractions; small or moderate numbers of spontaneous simultaneous contractions; occasional repetitive contractions; and the presence of some mildly prolonged (10-12s) contractions. 


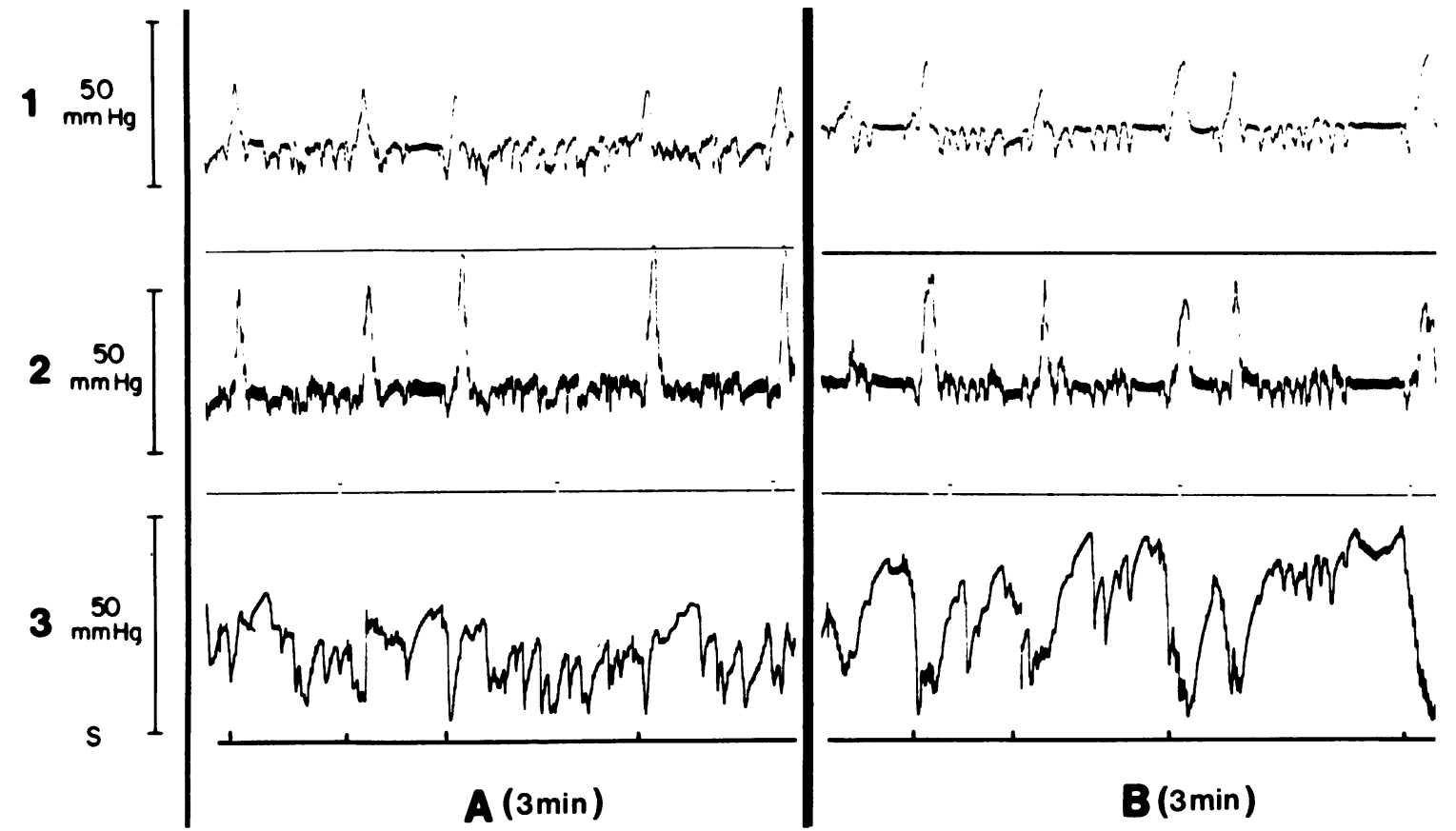

Fig. 1 Positive ergometrine test showing a rise in LOSP. Oesophageal pressure on the LOS (3), $5 \mathrm{~cm}$ (2) and $10 \mathrm{~cm}(1)$ proximal to this site; $A$, before and $B$, after $0.5 \mathrm{mg}$ intravenous ergometrine. A substantial rise in pressure to $45 \mathrm{~mm} \mathrm{Hg}$ occurred in the LOS with ergometrine and was associated with continuous pain. The vertical marks on the lowest line(s) indicate swallows.

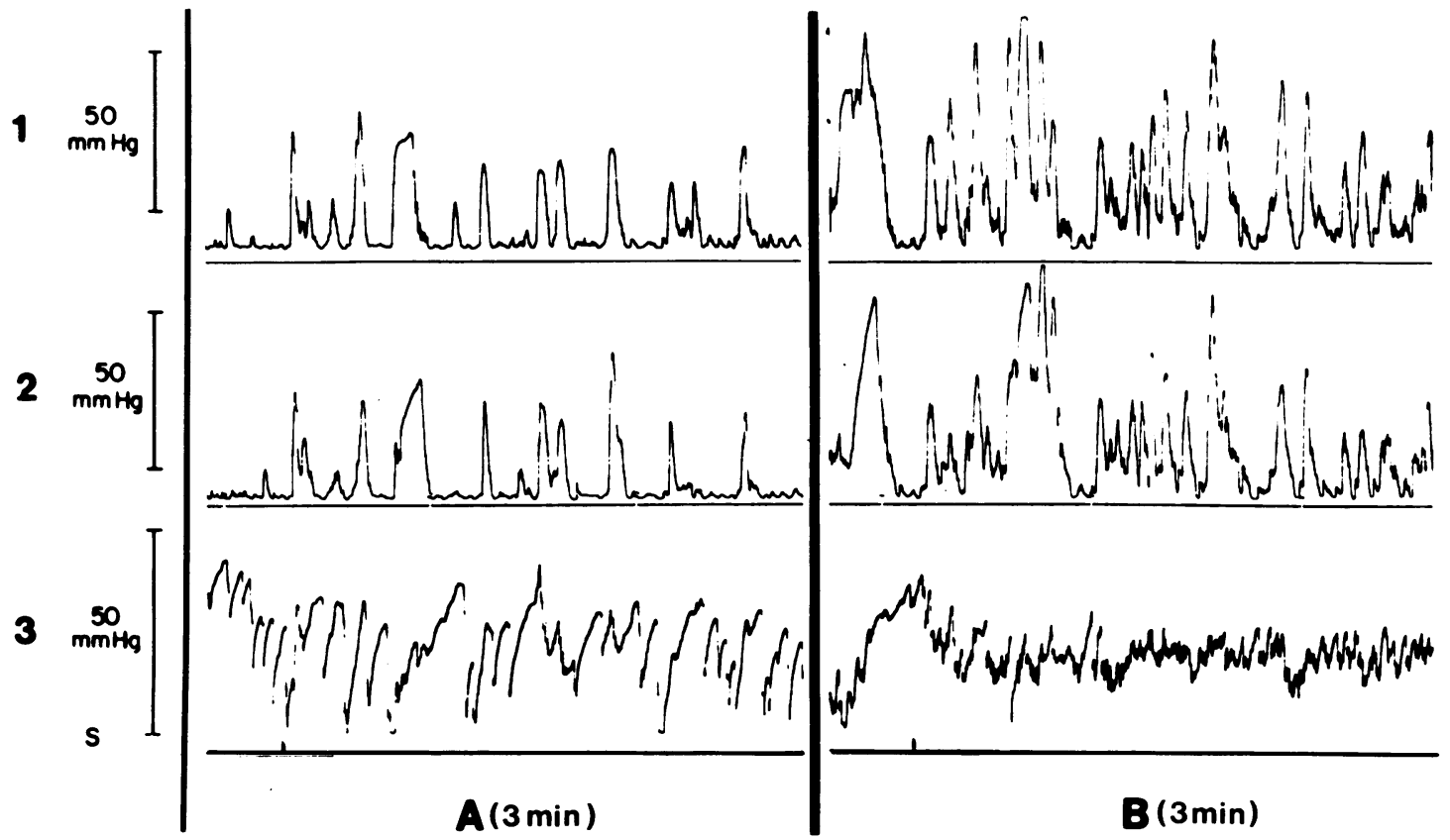

Fig. 2 Positive ergometrine test. Oesophageal pressure in the $L O S$ (3), $5 \mathrm{~cm}$ (2) and $10 \mathrm{~cm}$ (1) proximal to the sphincter; $A$, before and $B$, after $0.5 \mathrm{mg}$ intravenous ergometrine. In $A$ there are non-specific abnormalities with a high proportion of simultaneous contractions, some of which are slightly prolonged or repetitive. In $B$ there is oesophageal spasm, associated with the patient's familiar pain. The vertical marks on the lowest line(s) indicate swallows. 
The amplitude of the three strongest and the duration of the three longest contractions in each trace were measured and averages recorded. The proportion of simultaneous, as opposed to peristaltic responses to swallowing was also recorded.

Before the code was broken an attempt was made to judge which trace from an individual showed the greater number of abnormalities. A judgment was not recorded in cases where it was felt that differences between traces were too small to decide with confidence.

\section{Interpretation of ergometrine provocation test}

During the course of this work, four arbitrary criteria emerged which identified a positive result (Fig. 2): (1) patients had spontaneous angina-like pain before the test; (2) with ergometrine, the patients' familiar pain was reproduced; (3) the ergometrine-induced pain was associated with a deterioration in oesophageal motility; and (4) during the test there was no change in the 12-lead electrocardiogram indicating myocardial ischaemia.

\section{Radiographic studies}

The oesophagus was examined by ciné-radiography. Standard procedures, which included exerting abdominal pressure and tilting head downwards, were used to provoke gastro-oesophageal reflux. Controls were not studied by radiography

\section{CONTROL GROUP B}

The six volunteers with coronary artery stenosis first had standard oesophageal manometry and then exercised on a bicycle ergometer. Load was increased at a constant speed until angina was experienced; at this point subjects were instructed to remain as still as possible and oesophageal motility was monitored until the pain subsided. These traces were not interpreted 'blind'.

Table 1 Oesophageal motility at rest and after ergometrine provocation in 42 patients with angina-like chest pain but no cardiac abnormality

\begin{tabular}{llll}
\hline & \multicolumn{1}{l}{ At rest } & \\
\cline { 2 - 4 } & Normal & $\begin{array}{l}\text { Non-specific } \\
\text { abmormality } \\
14\end{array}$ & Spasm \\
\hline $\begin{array}{l}\text { Normal after } \\
\text { ergometrine } 9\end{array}$ & 21 & & \\
$\begin{array}{l}\text { Non-specific } \\
\text { abnormality } \\
\text { after ergometrine } 11\end{array}$ & $9(1)$ & $4(1)$ \\
$\begin{array}{l}\text { Spasm after } \\
\text { ergometrine } 22\end{array}$ & $5(6)$ & $10(7)$ \\
\hline $\begin{array}{l}\text { Numbers in parentheses indicate patients who developed chest pain after } \\
\text { ergometrine. }\end{array}$
\end{tabular}

Results

CHEST PAIN GROUP

Oesophageal manometry

Resting studies No subject experienced chest pain during observation at rest. Half of them (21) had normal motility at rest; 14 had non-specific abnormalities, and, seven had oesophageal spasm. No patient showed manometric features of achalasia, as peristalsis was present in every trace and the five patients with a raised $(>25 \mathrm{~mm} \mathrm{Hg})$ resting LOSP showed normal relaxation after swallows.

Responses to ergometrine Twenty-seven of the 42 patients experienced chest pain after the injection of ergometrine (Table 1). In every case it was similar to their presenting complaint, although severity varied and the radiation was not always identical with their familiar pain. Two patients had repeated episodes of chest pain after ergometrine and in both cases the episodes of pain correlated well with manometric abnormalities (Fig. 3). There was no significant change in the motility records after ergometrine in 14 patients; resting motility had been normal in nine of these, had shown non-specific abnormalities in four, and in one patient with spasm at rest there was no change in the degree of abnormality after ergometrine. Three of these patients, however, developed chest pain with ergometrine (one with a normal trace, one with non-specific abnormalities, and one with spasm).

Oesophageal spasm was seen in 22 patients after ergometrine: resting traces had been normal in five, had shown non-specific abnormalities in 10, while another seven had spasm at rest; and six of this last group had an increase in abnormality after ergometrine. Nineteen of the 22 patients with spasm had pain after ergometrine and another patient had previously experienced pain with ergometrine at the time of coronary angiography. There were seven patients with normal traces at rest who developed non-specific abnormality and six of these had ergometrine-induced chest pain.

Ergometrine provocation tests were positive in a total of 24 patients. In every case there was significant deterioration of motility during ergometrine-induced pain; 18 patients had spasm after ergometrine, 12 with normal traces or non-specific abnormalities at rest, and six with asymptomatic spasm at rest who showed a definite increase in abnormality after ergometrine. The other six patients with a positive ergometrine test had normal traces at rest and developed non-specific abnormalities during ergometrine-induced pain.

Ergometrine increased the amplitude and duration of oesophageal contractions as well as increasing lower oesophageal sphinter pressure (Table 2). The largest increases in both amplitude and duration of contractions were seen in the patients who developed 


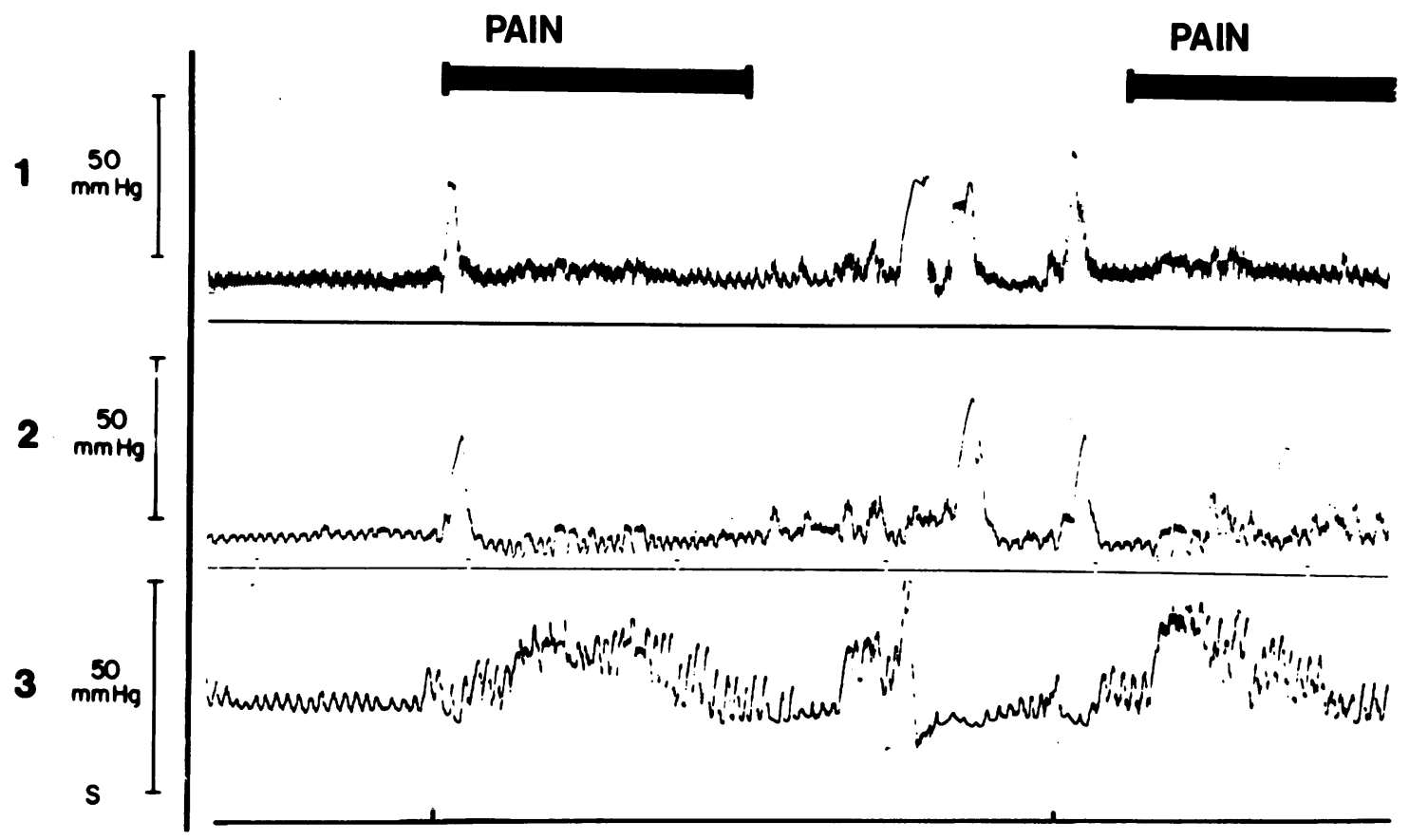

(6min)

Fig. 3 Positive ergometrine test with intermittent chest pain. Oesophageal pressure in the LOS (3) and $5 \mathrm{~cm}$ and $10 \mathrm{~cm}$ proximal to this site ( 2 and 1$)$, after intravenous ergometrine $0.5 \mathrm{mg}$. Chest pain occurred only in association with two periods of raised LOSP. Peristalsis remained normal throughout the trace.

Table 2 Measurements of oesophageal manometry before and after ergometrine in 42 patients and 10 asymptomatic volunteers (control group A)

\begin{tabular}{|c|c|c|c|c|c|c|c|c|c|}
\hline & \multicolumn{2}{|c|}{ Amplitude $(\mathrm{mm} \mathrm{Hg})$} & \multicolumn{2}{|l|}{ Duration (s) } & \multicolumn{3}{|c|}{$\begin{array}{l}\text { \% Simultaneous } \\
\text { contractions }\end{array}$} & \multirow{2}{*}{$\begin{array}{l}\begin{array}{l}\operatorname{LOSP} \\
(\mathrm{mm} \mathrm{Hg})\end{array} \\
{ }_{\text {At rest }}\end{array}$} & \multirow[t]{2}{*}{$\begin{array}{l}\triangle L O S P \\
(\mathrm{~mm} H g)\end{array}$} \\
\hline & Control & Ergometrine & Control & Ergometrine & & Control & Ergometrine & & \\
\hline $\begin{array}{l}\text { Pain with ergometrine (27) } \\
\text { No pain with ergometrine (15) } \\
\text { Control subjects (group A) (I0) }\end{array}$ & $\begin{array}{l}53 \cdot 2 \pm 3 \cdot 4 \\
43 \cdot 1 \pm 4 \cdot 3 \\
40 \cdot 9 \pm 5 \cdot 5\end{array}$ & $\begin{array}{l}63 \cdot 2 \ddagger \pm 4 \cdot 1 \\
48 \cdot 3^{*} \pm 4 \cdot 7 \\
42 \cdot 7^{*} \pm 5 \cdot 1\end{array}$ & $\begin{array}{l}10.1 \pm 0.5 \\
9.3 \pm 0.5 \\
10.6 \pm 0.8\end{array}$ & $\begin{array}{l}13 \cdot 2+ \pm 1 \cdot 1 \\
10 \cdot 2 * 0.8 \\
10 \cdot 9 \pm 0.8\end{array}$ & ○ & $\begin{array}{l}32.9 \pm 5.5 \\
14.3 \pm 3.9 \\
16.8 \pm 7 \cdot 2\end{array}$ & $\begin{array}{l}42 \cdot 6 \pm \pm 4 \cdot 9 \\
26 \cdot 1 \ddagger \pm 5 \cdot 1 \\
31 \cdot 3 \pm 8 \cdot 4\end{array}$ & $\begin{array}{l}17 \cdot 0 \pm 2 \cdot 7 \\
14 \cdot 7 \pm 2 \cdot 6 \\
15 \cdot 3 \pm 1 \cdot 9\end{array}$ & $\begin{array}{l}++11.2 \\
+2.3 \\
+1.9\end{array}$ \\
\hline
\end{tabular}

The means \pm SEM of the amplitude and duration of the three strongest and the three longest contractions are shown. Lower oesophageal sphincter pressure at rest and change after ergometrine $\left(\triangle\right.$ LOSP) are given. Significant differences (paired $t$ test) between pre- and post-ergometrine values: ${ }^{\bullet} P<0.05$. $\dagger P<0.01$. $\ddagger P<0.001$.

pain after ergometrine. Simultaneous contractions were approximately twice as common at rest in those who developed chest pain; after ergometrine both groups had a highly significant increase in the number of simultaneous contractions. There was a significant increase in LOSP in the patients who developed pain after ergometrine ( $66 \%$ above resting levels); the other patients showed no significant change.

Radiographic studies Results of barium swallow examination are shown in Table 3. There was very poor correlation between abnormalities seen radiographically and by manometry. Radiographic signs of oesophageal spasm were observed in five patients, but only three of them had a positive ergometrine test; the others had no pain after ergometrine, although they both developed oesophageal spasm, and one had ergometrine-induced pain at another occasion. In none of the seven patients with manometric signs of spasm at rest was this change shown radiographically.

CONTROL GROUP A

Motility patterns of the 10 asymptomatic volunteers before and after ergometrine are shown in Table 4. There was a high incidence of abnormal resting 
Table 3 Results of barium swallow examination compared with oesophageal manametry

\begin{tabular}{|c|c|c|c|c|c|}
\hline \multirow{2}{*}{$\begin{array}{l}\text { Abnormalities of barium } \\
\text { swallow examination }\end{array}$} & \multicolumn{3}{|c|}{ Standard oesophageal manomery (42) } & \multicolumn{2}{|c|}{ Ergometrine provocation test (42) } \\
\hline & Normal (2l) & $\begin{array}{l}\text { Non-specific } \\
\text { abnormality (14) }\end{array}$ & Spasm (7) & Negative (18) & Positive (24) \\
\hline $\begin{array}{l}\text { Hiatus hernia and/or gastro-oes. } \\
\text { reflux (\%) } \\
\text { Abnormal motility }-3^{\circ} \text { waves (\%) } \\
\text { Abnormal motility - spasm (\%) }\end{array}$ & $\begin{array}{r}48 \\
38 \\
5\end{array}$ & $\begin{array}{l}43 \\
29 \\
29\end{array}$ & $\begin{array}{r}14 \\
29 \\
0\end{array}$ & $\begin{array}{l}50 \\
39 \\
11\end{array}$ & $\begin{array}{l}29 \\
29 \\
12\end{array}$ \\
\hline
\end{tabular}

Number of patients in parentheses. 'Spasm' denotes gross abnormality of oesophageal motility such as 'cork-screw oesophagus' or 'pseudo diverticula'; tertiary waves are non-propulsive contractions.

motility; one had oesophageal spasm and five had non-specific abnormalities. Motility after ergometrine remained non-specifically abnormal in three of these subjects; the other three showed spasm and two of them had chest pain. Both were nurses and had not previously experienced this pain, but were able to identify it as similar to descriptions of angina.

One of the four subjects with normal motility at rest developed non-specific abnormalities after ergometrine. None had pain.

There was a small but significant increase in the amplitude of oesophageal contractions after ergometrine, but no significant change in the duration of contractions, the percentage of simultaneous contractions, or in the LOSP.

Table 4 Oesophageal motility at rest and after ergometrine provocation in 10 asymptomatic volunteers (control group A)

\begin{tabular}{llll}
\hline $\begin{array}{l}\text { After } \\
\text { ergometrine }\end{array}$ & \multicolumn{1}{l}{ At rest } & \\
\cline { 2 - 4 } & Normal & $\begin{array}{l}\text { Non-specific } \\
\text { abnormality } \\
\text { S }\end{array}$ & Spasm \\
\hline $\begin{array}{l}\text { Normal 3 } \\
\text { Non-specific }\end{array}$ & $3(0)$ & & $l$ \\
abnormality 4 & $1(0)$ & $3(0)$ & \\
Spasm 3 & 0 & $2(1)$ & $1(1)$ \\
\hline
\end{tabular}

Numbers in parentheses indicate patients who developed chest pain after ergometrine.

\section{Accuracy of assignments}

A 'blind' assessment of which trace from a given individual showed more abnormalities was made in two-thirds of the subjects; the control and postergometrine traces were indistinguishable in the remainder (Table 5). In every case where assessment was attempted, the more abnormal motility corresponded with the ergometrine period, including those in which control and ergometrine traces were judged to be in the same category-for example, 'spasm' or 'non-specific abnormalities'. Although the
Table 5 Accuracy of assignments of oesophageal manometric records

\begin{tabular}{lccc}
\hline & \multicolumn{2}{l}{ Assignments } & \\
\cline { 2 - 4 } & Correct & Not made & Wrong \\
\hline Patients (42) & 23 & 4 & - \\
Pain with ergometrine (27) & 4 & 11 & - \\
No pain with ergometrine (15) & & & - \\
Controls (10) & 2 & - & - \\
Pain with ergometrine (2) & 4 & 4 & \\
No pain with ergometrine (8) & & & \\
\hline
\end{tabular}

During 'blind' interpretation of the manometric records the investigator decided which of the traces from a given individual showed more abnormality. Assignments were made only when he was reasonably confident of a difference between traces, but it was not necessary that there was any change in category-that is, normal to non-specific abnormality-see text-between the traces. The traces were then decoded and matched with control or ergometrine injection periods. When the more abnormal trace corresponded to the ergometrine injection period the assignment was said to be correct.

frequency with which saline and ergometrine traces could be reliably distinguished was much greater in those who developed chest pain than in those who did not, these results indicate that ergometrine causes changes in oesophageal motility not only in many of the patients with chest pain but also in some asymptomatic subjects.

\section{CONTROL GROUP B}

Three of the six volunteers with coronary artery stenosis had normal oesophageal motility at rest, and the others had non-specific abnormalities. Artefacts produced by laboured breathing after exertion prevented accurate measurements of oesophageal contractile amplitude and LOS pressures may have been recorded inaccurately because of displacement of the catheter during exercise. Two of them developed minor abnormalities of motility during angina with an increase in the number of simultaneous contractions (Fig. 4); two had no change; the remaining two had fewer simultaneous contractions during angina than at rest. The four volunteers with minor changes in oesophageal motility during angina remained in the same category-that is, normal or non-specific abnormalities. 


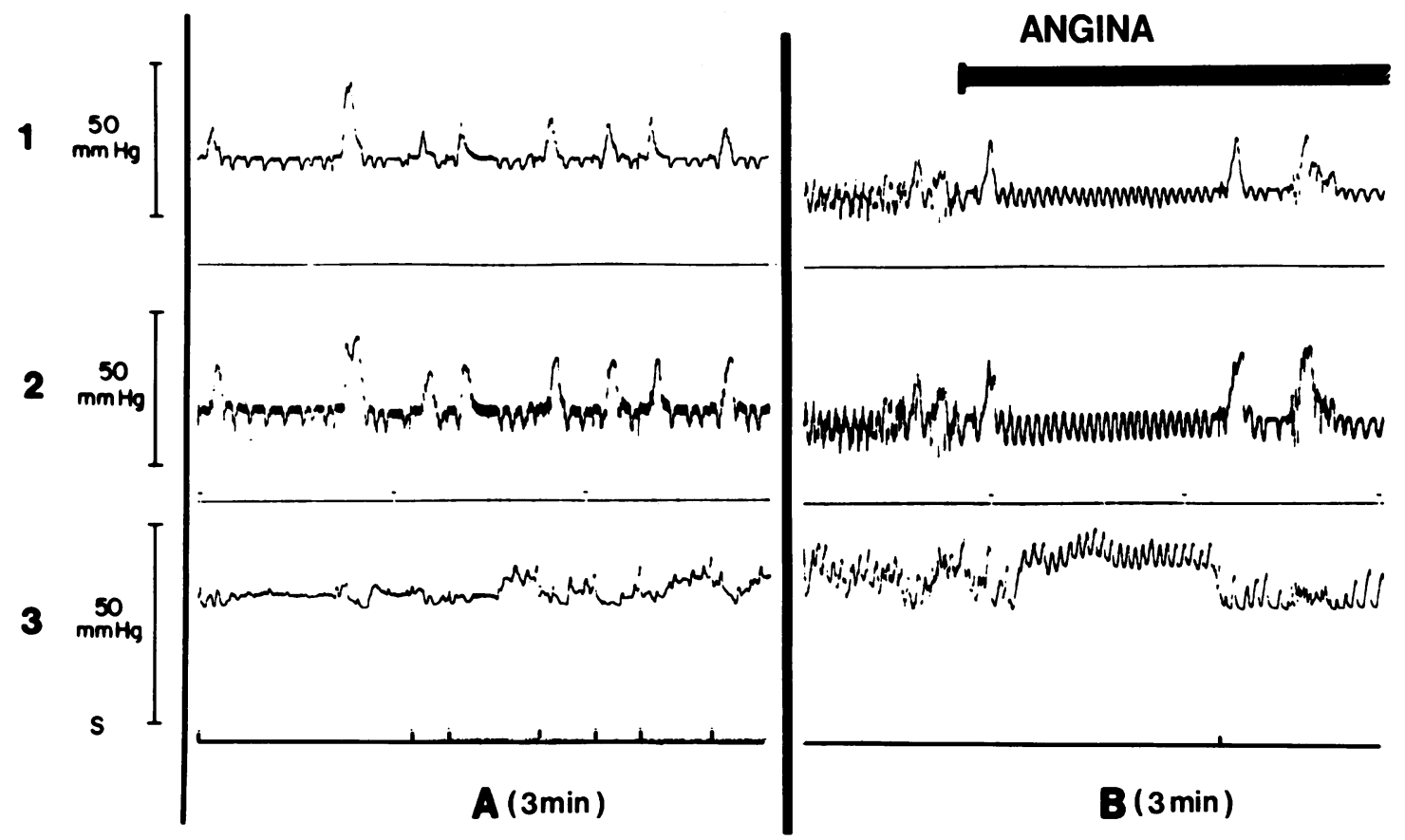

Fig. 4 Oesophageal manometry during exertional angina. Oesophageal pressure in the LOS (3), $5 \mathrm{~cm}$ and $10 \mathrm{~cm}(2$ and I) proximal to this site. Trace $A$ is at rest; $B$ is during and after cycling on an ergometer. At the onset of angina (shown by the hatched bar) the subject remained still and the only change from normal motility was a single simultaneous contraction.

\section{Discussion}

Recurrent chest pain of anginal character in patients with an apparently normal heart is a formidable clinical problem. Of our 42 patients in this category it was possible to make a diagnosis of oesophageal spasm in only 12 patients, using standard tests which included a barium swallow examination and oesophageal manometry without provocation. The diagnosis was made in another 15 patients in the group by ergometrine provocation, which caused both pain and a deterioration in oesophageal motility. Of the remaining 15 patients, all of whom continued to have pain after at least two years, ergometrine produced an effect in four-two had dysmotility without pain and two had pain without dysmotility. There was no evidence to support oesophageal disease in the remaining 11 patients. Oesophageal spasm, therefore, appeared to be responsible for symptoms in 27 of our 42 patients and the ergometrine provocation test alone established the diagnosis in 15 of these. As all of these patients were fully convinced that they had heart disease, to establish the diagnosis of a relatively benign condition was of considerable importance to them.

Although abnormalities of oesophageal motility are found in asymptomatic subjects we were surprised to observe that one of our 10 volunteers had marked, but asymptomatic, spasm, and that only four had completely normal traces at rest. Ergometrine produced pain in two volunteers both of whom had abnormal traces at rest and spasm after provocation. These subjects had not previously experienced pain, but should probably be regarded as having 'latent oesophageal spasm'. Our results show that ergometrine causes deterioration in oesophageal motility, not only in a high proportion of patients with non-cardiac chest pain, but also in some healthy asymptomatic subjects.

The absence of important oesophageal abnormalities during exertional angina in our six volunteers with coronary artery stenosis (control group B) suggests that oesophageal dysmotility is not a nonspecific change accompanying chest pain, but a definite abnormality which, in some subjects, may produce symptoms identical with those of myocardial ischaemia. The minor changes seen in two of these volunteers during exercise-induced angina are similar to those Rubin ${ }^{1}$ observed in subjects during a traumatic interview and may well be produced by an increase of adrenergic tone.

The rate of response of the manometric system after occlusion of a perfusion channel is generally 
considered adequate for oesophageal motility studies, although the compliance is certainly greater than that of a pneumo-hydraulic infusion apparatus. ${ }^{2}$ Because of this, the amplitude of some powerful contractions was undoubtedly underestimated. Moreover, in some traces recording pens reached full excursion before the peak contraction pressure had occurred, which also led to underestimation of amplitudes. For these reasons, contractile amplitudes in traces designated as 'spasm' tended to be lower than those reported by others using more sensitive systems. Allowance was made for these factors during interpretation of manometric records, but, as the highest contractile amplitudes were observed in the 27 patients who developed pain during the test, changes with ergometrine may have been underestimated and the number of positive tests underdiagnosed. Any such tendency would not affect the validity of the conclusions.

Intravenous ergometrine can cause myocardial ischaemia in people with fixed coronary artery stenosis $^{3}$ as well as in those who are susceptible to coronary artery spasm. ${ }^{4}$ Three deaths have been reported recently after intravenous ergometrine caused coronary artery spasm that failed to respond to nitrates. ${ }^{5}$ Buxton concluded that the most important factor related to refractory vaso-spasm after the administration of ergometrine during angiography was the total dose given. In fatal cases the minimum dose used was $1.7 \mathrm{mg}$ and it is our recommendation that no more than $0.5 \mathrm{mg}$ of intravenous ergometrine be given for the diagnosis of oesophageal spasm. Larger doses increase the risk of the procedure and limited studies carried out by us suggest that they do not increase sensitivity. It is very important that all possible steps be taken to exclude coronary artery disease and variant angina before ergometrine is given. Electrocardiographs must be taken after an exercise test and during a spontaneous attack of pain; if there is any evidence of myocardial ischaemia additional cardiological investigations, including coronary angiography, must be done first. If the coronary arteries are normal, ergometrine can be given at that time with the advantage that nitrates can be injected directly into the coronary arteries to reverse vasospasm. ${ }^{6}$

If these precautions are taken, it is most unlikely that problems will be encountered. With this proviso, the ergometrine provocation test can be considered safe, although full resuscitation facilities should nevertheless be at hand. The only complications we have recognised is vomiting in about $5 \%$ of those given ergometrine and some subjects have an uncomfortable, flushed feeling for a short time. We have already reported on ergometrine provocation in the diagnosis of oesophageal spasm in 13 patients ${ }^{7}$ and this test has been used by others. ${ }^{89}$ The results suggest that it is more sensitive than barium swallow and standard manometric studies but we are unable to compare it directly with other provocative tests for oesophageal spasm. Provocation with intravenous bethanecol, ${ }^{10}$ intravenous edrophonium, ${ }^{10}$ and intravenous pentagastrin ${ }^{11}$ have been tried but, as none has been widely acclaimed, the introduction of a new provocative test is justified. In reporting the use of ergometrine provocation in the Coronary Care Unit for the diagnosis of variant angina, Waters ${ }^{12}$ was unable to explain the occurrence of typical chest pain in 37 of the 64 patients with a negative test-that is, no ECG changes. The high incidence of ergometrine-induced chest pain in this group may have been due to undiagnosed oesophageal spasm and suggests the need for oesophageal investigations in such patients.

Our 42 patients were highly selected, and not truly representative of most patients with oesophageal spasm. They have regularly attended follow-up clinics for between two and five years because of 'angina' and in $90 \%$ of the group exercise regularly provoked pain. None of the patients had presented to his doctor with any other oesophageal sympton, and these were either absent or very much overshadowed by the severe chest pain. In particular, dysphagia, which is frequent in patients with idiopathic spasm was unusual in our group, and only a few of them had gastro-oesophageal reflux, which may provoke oesophageal spasm in certain susceptible individuals. The fact that 19 of them had two coronary angiograms is perhaps some indication of the severity of their symptoms and the frustration of their medical attendants!

The pain produced by oesophageal spasm commonly imitates myocardial ischaemia. In our follow-up study of 98 patients with cardiac-like chest pain and normal coronary arteries, we found that oesophageal spasm was responsible in 16 of the 22 patients who agreed to reinvestigation because of recurrent pain. ${ }^{13}$ Other studies have confirmed that oesophageal pain, particularly due to oesophageal spasm, frequently mimics myocardial ischaemia. ${ }^{14}$ Approximately one in seven patients presenting as an emergency with suspected myocardial ischaemia is later shown to have oesophageal pain ${ }^{15}$ and the oesophagus is responsible for angina-like symptoms in a similar proportion of those who were thought to have had cardiac disease until coronary angiography shows normal arteries. ${ }^{131617}$ Patients may have all the clinical features of angina pectoris without any telltale symptoms of oesophageal disease, and a mistaken diagnosis may have devastating consequences as they become disabled by the imposed restrictions and are 'cardiac cripples' in spite of their normal hearts. Reassurance that the heart is normal is often not 
enough for patients with recurrent severe pain. In Ockene's study ${ }^{18} 44 \%$ of those given this negative but optimistic outlook still believed they had heart disease some time later. For this reason it is important to make a positive diagnosis as early as possible in patients who have angina-like pain but no evidence of cardiac abnormality. In $55 \%$ of our patients with oesophageal spasm, the diagnosis was made only by ergometrine provocation.

We gratefully acknowledge technical assistance from Mr R H Lowndes, the University Department of Surgery, for providing facilities, and the Department of Medical Illustration for prints. HAD was supported by a grant from the Welsh Scheme for the Developoment of Social and Health Research.

\section{References}

'Rubin J, Nagler R, Spiro HM, Pilot ML. Measuring the effect of emotions on esophageal motility. Psychom Med 1962; 24:170-6.

${ }^{2}$ Arndorfer RC, Stef JJ, Dodds WJ, Linehan JH, Hogan WJ. Improved infusion system for intraluminal esophageal manometry. Gastroenterology 1977; 73:23-7.

${ }^{3}$ Stein I. Observations on the action of ergonovine on the coronary circulation and its use in the diagnosis of coronary artery insufficiency. Am Heart $J$ 1949: 37:36-45. ${ }^{4}$ Maseri A, Pesola A, Marzilli M, Severi S, Parodi O, L'Abbate A, Ballestra AM, Maltinti G, Denes DM, Biagini A. Coronary vasospasm in angina pectoris. Lancet 1977; 1:716-7.

sBuxton A, Goldberg S, Hirshfeld JW, Wilson J, Mann T, Williams DO, Overlie P, Oliva P. Refractory ergonovineinduced coronary vasospasm: importance of intracoronary introglycerin. Am J Cardiol 1980: 46:329-34.
${ }^{6}$ Heupler FA. Provocative testing for coronary artery spasm: risk, method and rationale (Editorial). Am J Cardiol 1980: 46:335-7.

'Dart AM, Alban Davies H, Lowndes RH, Dalal J, Ruttley $\mathrm{M}$, Henderson $\mathrm{AH}$. Oesophageal spasm and angina: diagnostic value of ergometrine (ergonovine) provocation. Eur Heart J 1980; 1:91-5.

${ }^{8}$ Dickerson J, Eastwood G, Weiner B, Ockene I, Haffajee C. Use of ergonovine to identify patients with chest pain due to esophageal spasm. (Abstract). Gastroenterology 1980; 78:1156.

${ }^{9}$ Koch KL, Long A, Curry C, Mathias JR. The ergonovine stress test: a provocative test for diffuse esophageal spasm or variant angina? (Abstract). Am J Cardiol 1980; 45:440.

${ }^{10}$ Mellow M. Manometric follow-up and response to cholinergic stimulation and cholinesterase inhibition. Gastroenterology 1977; 73:237-40.

"Orlando RC, Bozymski EM. The effects of pentagastrin in achalasia and diffuse esophageal spasm. Gastroenterology 1979; 77:472-7.

${ }^{12}$ Waters DD, Theroux P, Szlachcic J, Dauwe F, Crittin J, Bonan R, Mizgala HF. Ergonovine testing in a coronary care unit. AM J Cardiol 1980; 46:922-30.

13Dart AM, Alban Davies H, Dalal J, Ruttley M, Henderson AH. 'Angina' and normal coronary arteriograms: a followup study. Eur Heart $J$ 1980; 1:97-100.

${ }^{14}$ Alban Davies H, Rhodes J. How often does the gut cause anginal pain? Acta Medica Scand [Suppl] 1981; 644:62-5.

${ }^{15}$ Bennett JR, Atkinson M. The differentiation between oesophageal and cardiac pain. Lancet 1966; 2:1123-7.

${ }^{16}$ Brand DL, Martin D, Pope CE II. Esophageal manometrics in patients with angina-like chest pain. Dig Dis 1977 ; 22:300-4.

"Delmonico JE, Black A, Gensini CG. Diaphragmatic hiatal hernia and angina pectoris. Dis Chest 1968; 53:309-15.

${ }^{18}$ Ockene IS, Shay MJ, Alpert JS, Weiner BH, Dalen JE. Unexplained chest pain in patients with normal coronary arteriograms. $N$ Engl J Med 1980; 303:1249-52. 